\title{
On the Causes and Countermeasures of Chinese Learners’ English Reading Anxiety
}

\author{
Xiaoli Gan \\ School of Foreign Languages, Sichuan University of Arts and Science, Dazhou, Sichuan 635000, China

\begin{abstract}
Based on Humanistic Psychology and Krashen's Affective Filtering Hypothesis, this study explores the effects on English reading anxiety among Chinese students, and corresponding countermeasures are put forward to it. English reading anxiety, one of the emotional factors that have a great effect on foreign language learning, mainly refers to the feeling of not being able to achieve desired goal or overcome a mental obstacle. The results indicate that Chinese English learners suffer English reading anxiety in text comprehension, and the psychological, cultural and text factors are the main causes leading to it. Based upon the findings, its advisable to lower the learners' affective filter and promote their self-confidence as well as cultivate their cross-cultural awareness in future English reading teaching.
\end{abstract}

Index Terms — anxiety, reading anxiety, affective filtering hypothesis, cross-cultural awareness

\section{INTRODUCTION}

Reading used to be regarded as an individual activity and intrapersonal problem-solving task which happens within a person's brain, and it did not involve the interaction like speaking did (Bernhardt, 1991). Consequently, affective factors in second language reading, such as anxiety, were neglected. Actually, reading was an active meaning constructing process from a sociocognitive perspective (Bernhardt, 1991) in that readers played an important role in reading comprehension. For instance, readers interacted with texts which may bring about different interpretations of the text based on the readers' background knowledge and language knowledge itself. With the development of humanistic psychology, more and more attention has been paid to the affective factors in education. Language learning is a complex process which involves many factors, such as motivation, emotion, cognition, personality, and so on (Arnold, 2005, p.80). Anxiety, as one of the critical emotional factors in language learning, has become one of the hottest topics in the study of second language acquisition at home and abroad since 1970s. Most of the studies only focus on foreign language learning anxiety in a broad sense. Saito and his partners (1990) first put forward the concept of "Foreign Language Reading Anxiety" and illustrated the differences and relations between "Foreign Language Learning Anxiety" and "Foreign Language Reading Anxiety", and designed the "Foreign Language Reading Anxiety Scale"(FLRAS) to test the reading anxiety levels of the participants.

In China, the researches on foreign language anxiety mainly focus on the general English learning anxiety. Foreign language reading anxiety, as a kind of negative emotion in the process of foreign language reading, is a psychological phenomenon of discomfort, anxiety or even fear caused by readers' failure to reach the expected goal or overcome the obstacles in the process of reading (Zhao Yunli, 2009). The main research result is that there is a negative correlation between foreign language anxiety and reading performance. The researches on the relationship between affective factors and English teaching in China, however, started relatively late, and it doesn't get due attention by domestic scholars. This paper aims to explore the causes of English reading anxiety among Chinese learners, and attempt to put forward the corresponding countermeasures according to the results of the research.

\section{LITERATURE REVIEW}

Anxiety is the tension and anxiety caused by an individual's failure to achieve a certain goal. According to Spielberger (1976), "anxiety is the subjective feeling of tension, apprehension, nervousness, and worry that are experienced by an individual," and the "heightened activity of the autonomic nervous system that accompanies these feelings". From the psychological perspective, anxiety is explained as "an unpleasant, complex and emotional state of tension and worry caused by the possible imminent danger or threat, which is a kind of fear of fear and worry of worry" (Huang Xiting, 2003). Horvitz (1986) sees anxiety as a subjective feeling of tension and anxiety. Anxiety is an emotional state in which an individual's self-esteem and self-confidence are frustrated, or the sense of failure and guilt increase due to the failure or inability to overcome the threat of obstacles.

Although most studies have shown that foreign language anxiety has a negative influence on the learning process and performance (Horwitz et al., 1986; MacIntyre \&Gardner, 1989; Phillips, 1992; Young, 1991), the relation between foreign language reading anxiety and foreign language reading performance is not so clear cut. Some studies demonstrate that foreign language reading anxiety negatively influences reading performance (Sellers, 2000; Shi \& Liu, 
2006) while some others show no significance in such a relationship (Brantemier, 2005; Mills, Pajares \& Herron, 2006; Zhao, 2009)."

\section{A. Affective Filter Hypothesis}

For different individuals, their language learning speed and efficiency vary diversely, hence the final language levels are different accordingly. According to Krashen's Affective Filtering Hypothesis, "understandable language input is only a necessary condition for language acquisition, not a sufficient one." To explain the differences in language learning results, language input should not be considered as a single factor. The different amount of language input is one possible explanation for this. Another possible one is the learners' different emotional factors.

According to Krashen, learning purpose, learning motivation, self-confidence, anxiety and so on are collectively called "affective filtering" factors. Once having clear purpose, high learning motivation, strong self-confidence and moderate anxiety, then the "affective filtering" for learners is weak, and vice versa. Krashen points out that only through the emotional filter can all the language input reach the language acquisition mechanism and be absorbed by the brain. In the process of language acquisition, if the "affective filtering" is too strong, obstacles are likely to be formed in the brain, and language input will be filtered. Consequently, language acquisition will not occur.

\section{B. Foreign Language Reading Anxiety}

The concept of "Foreign Language Anxiety" was first proposed by Horwitz (1986). He holds that foreign language learning anxiety is a unique synthesis of self-perception, belief, emotion and behavior arising from the processes of foreign language learning. Scholars have a variety of classifications for foreign language anxiety. For example, it can be classifies into Test Anxiety, Negative Evaluation Anxiety, State anxiety and so on. According to MacIntyre and Gardner (1994), "foreign language anxiety is a feeling of tension and fear that has a special relationship with the foreign language context."

Saito et al. (1999) defined foreign language reading anxiety as: "the anxiety that learners experience in reading a foreign language. It is related to but distinguishable from foreign language anxiety" (Saito, Y., Horwits, E. 1999). English reading anxiety is a negative emotion of readers in English reading, which is omnipresent in English reading (Saito etal, 1999). When it is difficult for individuals in the English reading situation to achieve expectations or when they encounter obstacles in reading, English reading anxiety caused by a kind of nervous fear arise, resulting in students' dissatisfactory performance in reading correspondingly.

\section{The Effect of Foreign Language Anxiety on Performance}

The effect of anxiety on learners' all aspects of academic performance has been examined for it is a common problem among foreign language learners. Comprehensively, early studies related to the relationship of foreign language anxiety and foreign language performance have generated mixed results, which showed that the relationship is a complex one. (Zhao, 2009). The relation of anxiety and foreign language performance is mediated by task difficulty and the intensity of anxiety (MacIntyre \& Gardner, 1991a; Williams, 1991). The different opinions might also be due to the inconsistent measurement or some unclear definitions of foreign language anxiety. According to Zhao (2009), most of the early studies in foreign language anxiety have a focus on speaking, and some studies have also drawn readers' attention to the anxiety that foreign language students might experience in the less examined skills of listening, writing and reading (Cheng, 2002; Cheng et al., 1999; Vogely, 1998). Foreign language reading anxiety, foreign language listening anxiety and foreign language writing anxiety are related to but distinct from foreign language anxiety (Zhao, 2009).

Although most studies (Huang, 2001; Saito et al., 1999; Shi \& Liu, 2006; Zhang, 2002) have showed that foreign language reading anxiety exists among foreign language learners, some other studies show that foreign language reading anxiety is not much of a concern to advanced language learners and foreign language reading anxiety level is related to the perceived difficulty level of the reading material and following reading tasks (Brantmeier, 2005). Generally speaking, while some studies showed that foreign language reading anxiety negatively affects foreign language reading process and also foreign language reading performance (Sellers, 2000; Shi \& Liu, 2006), some found no significant relationship (Brantemier, 2005; Milles, Pajares \& Herron, 2006, Zhao, 2009).

In English acquisition, reading, as an important means of language input, can measure English learners' language ability, so to improve their reading proficiency is super significant in English teaching. Therefore, it's essential to study the main barrier, reading anxiety, in English reading comprehension.

\section{Methodology And Results}

Reading is a complex activity, which involves multidimensional skills that includes a variety of linguistic, cognitive, and non-linguistic factors. Attempts to investigate the situation of English reading anxiety among Chinese college learners, this study aims to analyse the causes of English reading anxiety and put forward the some corresponding countermeasures to it.

\section{A. Research Design}

The participants involved are 89 college students from a southwest university in Sichuan province. All the students are selected randomly from 257 freshmen and sophomores. Table 1 shows the basic information of the participants. 
TABLE 1

THE BASIC INFORMATION OF THE SUBJECTS

\begin{tabular}{|c|c|c|}
\hline \multirow{2}{*}{ Gender } & Male & 35 \\
\cline { 2 - 3 } & Female & 54 \\
\hline \multirow{2}{*}{ Grade } & freshmen & 43 \\
\cline { 2 - 3 } & sophomores & 46 \\
\hline
\end{tabular}

\section{B. Results}

As it shows in Table 2, about $47.73 \%$ of the students feel frustrated while they're reading English articles which are sort of challenge for them, and only $40.04 \%$ students deny it. From the result it can be concluded that the participants are with fear, rejection and burden in English reading comprehension, which will generate negative influence in their reading performance correspondingly. This finding conforms to the result obtained by Shi and Liu (2006), in which they found the foreign language reading anxiety was negatively correlated to the reading performance scores among the college EFL students in China.

TABLE 2

PSYCHOLOGICAL EFFECTS ON ENGLISH READING ANXIETY

\begin{tabular}{|c|c|c|c|c|}
\hline PSYCHOLOGICAL EFFECTS ON ENGLISH READING ANXIETY \\
\begin{tabular}{|c|c|c|c|c|}
\hline Strongly disagree & Disagree & Neither agree nor disagree & Agree & Strongly agree \\
\hline $5.34 \%$ & $28.7 \%$ & $18.23 \%$ & $36.92 \%$ & $10.81 \%$ \\
\hline
\end{tabular}
\end{tabular}

During the process of reading, English learners sometimes cannot fully comprehend the meaning of the article even if they can identify most of the words in it. The possible reason lies in the different cultural background. Language, as a carrier of language, contains distinctive cultural connotations from social and cultural systems at a macroscopic level to the origins of specific words. This is the main cause why English learners have difficulty in understanding the text even though they know exactly the specific meaning of the words. Usually the cultural differences make it difficult for Chinese English learners to understand the true intention or connotation of the original text accurately, which tends to cause dysfunction and anxiety in them.

TABLE3

EFFECTS OF CULTURAL BACKGROUND ON ENGLISH READING ANXIETY

\begin{tabular}{|c|c|c|c|c|}
\hline Strongly disagree & disagree & $\begin{array}{c}\text { Neither agree } \\
\text { nor disagree }\end{array}$ & agree & Strongly agree \\
\hline $4.9 \%$ & $18.63 \%$ & $19.7 \%$ & $41.3 \%$ & $15.47 \%$ \\
\hline
\end{tabular}

We can see from Table 3 that $56.77 \%$ of the Chinese English learners regard that cultural as well as historical knowledge of English-speaking countries are especially significant for reading comprehension. Comparatively, only $23.53 \%$ of the students among the participants have doubt about the significance of the cultural and historical effects on English reading anxiety.

TABLE 4

EFFECTS OF TEXTS ON ENGLISH READING ANXIETY

\begin{tabular}{|c|c|c|c|c|c|}
\hline Questions & Strongly disagree & disagree & $\begin{array}{c}\text { Neither agree } \\
\text { nor disagree }\end{array}$ & $\begin{array}{c}\text { agree } \\
\text { Strongly } \\
\text { agree }\end{array}$ \\
\hline Difficulty & $4.2 \%$ & $12.7 \%$ & $7.8 \%$ & $34.6 \%$ & $40.7 \%$ \\
\hline Type of tasks & $6.9 \%$ & $15.5 \%$ & $14.7 \%$ & $30.8 \%$ & $32.1 \%$ \\
\hline Genre & $5.8 \%$ & $17.2 \%$ & $13.9 \%$ & $28.5 \%$ & $34.6 \%$ \\
\hline
\end{tabular}

The text, as one of the external factors on reading anxiety, exerts effects on learners reading comprehension performance greatly. The results in table 4 indicate that among the options causing anxiety in reading, $62.9 \%$ of the students chose the question types and $63.1 \%$ chose the article genre. As for the article genre, explanatory and narrative essays are involved. It is shown that most participants consider that multiple-choice questions are easier than essay questions. At the same time, they are likely to get more anxious when deal with much more difficult texts which contains more unknown vocabularies, more complex syntactic or grammatical structures. Hence it can be inferred that the difficulty of texts, the type of tasks and the article genre generally cause English reading anxiety to a certain extent.

\section{DISCUSSION}

\section{A. Affective Factors}

Affective filtering hypothesis, which consumes that learning a second language well or not is influenced by learners' emotion, is an important component of second language acquisition. Based on it, it's critical to filter emotions while learn a foreign language. Krashen's Second Language Acquisition theory emphasize that a large amount of appropriate language input cannot, definitely, enable students to learn a second language well, so the affective factors must be taken into account. Therefore during English reading, which is a key point in learning English, affective filtering should be adopted to stimulate students' enthusiasm so as to improve their confidence, clarify their reading purpose, reduce their stress and anxiety. Affective factors are the key elements in English reading. 
English reading anxiety mainly refers to the feeling of not being able to achieve desired goal or overcome a mental obstacle. The nervous mood, such a psychological abnormality, belongs to the category of psychology, and closely related with the lack of self-confidence in reading, which tends to arouse boredom and upset in learners. From the perspective of self-emotional experience, the score of English reading anxiety in Chinese college students is slightly high, which indicates that there is a certain level of anxiety in the process of English reading among them. The reason is that college students are likely to have a low sense of self-efficacy, which presents negative correlation with reading anxiety. That's to say, the higher it is, the lower their reading anxiety will be, and vice versa.

It is easy for the English learners to fall into anxiety due to psychological factors if they have low ambiguity tolerance during reading. The results indicate that Chinese English learners suffer English reading anxiety in text comprehension, which is probably caused by their low ambiguity tolerance. Lacking ambiguity tolerance of potential challenges may result in learners' seeking of clearly-defined solutions to ambiguous objects or information in task performance. According to Arnold (2005), learners who lack of ambiguity tolerance are more likely to encounter a lot of difficulties in foreign language learning. Therefore, learners with higher degree of ambiguity tolerance are usually less over-obsessed with the accuracy of reading. They can, whereas, adjust their thinking and mind according to the text during the process of reading without being influenced too much psychologically, then they can gradually grasp the thoughts of the article in the subsequent comprehension. Therefore, the teacher should help students build higher ambiguity of tolerance, and train them how to avoid emotional volatility to the maximum. In addition, teachers should infuse students with confidence and try to stimulate their inner motivations.

In the process of English learning, reading is one of the most vital ways of language input. So the negative emotions should get filtered in order to stimulate the enthusiasm of learners, improve their self-confidence, make clear their reading purpose and reduce their reading anxiety. It can be said that the affective factor is the key point to the successful training of reading ability.

\section{B. Cultural Differences}

This survey shows that the lack of necessary cultural background and confidence are the main causes to English reading anxiety. Saito et al. (1999) pointed out that unfamiliar cultural concepts rank only second to words and writing systems as triggers of reading anxiety because anxiety tends to arouse when a reader cannot comprehend the contextual meaning of the words due to a lack of cultural knowledge.

The English course in China mainly focus on the ability cultivation of listening, speaking, reading and writing, while not specialize in English cultural knowledge. Consequently, it leads to big gap between Chinese and Western cultures among Chinese students. It's well known that the receiving and decoding speed of verbal signal is determined by the foreign language experiences stored in brains, such as a certain number of perceptible vocabulary, some grammatical rules and the knowledge of related cultural background. The more experience is stored, the faster the speed of signal receiving and decoding is. Similarly, the fewer obstacles encountered in reading, the anxiety reduced in return. And vice versa.

As the carrier of culture, language and culture are inseparable from each other. To help Chinese students' reduce their anxiety in English reading and improve their reading ability, its vital to cover cultural knowledge in college English teaching. That's to say, English teachers should deepen students' understanding of cultural differences and try to bridge the gap between Western and Chinese cultures.

In fact, identifying with another kind of culture is not easy. At present, students have relatively little understanding of profound cultural knowledge, such as literature, art, history, values, ways of thinking, etc. When students read the original texts due to the "cultural conflict", their understanding and the author's original intention are different greatly, thus affecting the effect of reading and understanding, which may result in anxiety. Therefore, students should be appropriately exposed to more cultural background knowledge.

English, as a language subject, has rich cultural connotations. It is a vital communication tool as well as cultural carrier. Language knowledge and skills are the foundation of language competence, while intercultural awareness is guarantee of proper use of language. Therefore, more focus should be shifted to the cultivation of language competence and cultural consciousness in English teaching, so as to promote the all-round development of students and their humanities education. For instance, in the pre-reading or lead-in process, the students can be guided to have in-depth discussion about the background reflected in the reading materials, such as emotions, religious tradition and ways of life. To have a certain cross-cultural awareness, in return, will also be conducive to the deep comprehension of the articles.

Teachers should break the traditional teaching mode, such as the limitations of the teaching materials to include some classic literary works and some films popular among students. Meanwhile, some current affairs and the BBC and VOA broadcast can be favorable materials to rich students' cultural knowledge. How to effectively help the learners to broaden the knowledge in cultures, and lower their reading anxiety and ultimately improve their reading ability are still worthwhile for further study in English teaching and research.

\section{CONCLUSION}

Anxiety is one of the emotional factors that have a great effect on foreign language learning, which is a construct that is related to but distinct from general foreign language anxiety. It related to speaking a foreign language is usually more 
easily detected by instructors. However, anxiety related to reading is not easily noticed compared with spoken, since reading does not require the spontaneous interaction that speaking does. According to the sociocognitive perspective of reading (Bernhardt, 1991), reading is a meaning-reconstruction process where readers interact with not only the text-based components but also the extra-text components of a reading passage. Text-based components are such as word recognition, phonemic or graphemic decoding, and syntactic features. Most early studies on foreign language anxiety have focused on speaking, and foreign language reading anxiety research did not begin until recently (Saito et al., 1999). Many fundamental questions concerning foreign language reading anxiety such as the source of foreign language reading anxiety, the relation between foreign language reading anxiety and foreign language reading performance, and the relation between background variables and foreign language reading anxiety are still waiting for answers.

Language knowledge as well as skills is the basis of language proficiency, and cross-cultural awareness is the guarantee of appropriate language using. Therefore, more attention should be paid to the cultivation of cultural awareness in English teaching. Through this study, we explored the factors on Chinese students' English reading anxiety, which are psychological, cultural and text effects and provide some pedagogical implications to English teaching. It suggests that in the future teaching, some strategies to reduce anxiety should be designed and the difficulty of English reading corpus should be strictly controlled. At the same time, we should take into consideration of the different levels of reading anxiety between male and female students, so as to achieve the purpose of improving the effectiveness of reading teaching. Hopefully, case study and classroom observation would be applied to investigate reading anxiety in future studies.

\section{REFERENCES}

[1] Aiping, Zhao. (2009). Foreign Language Reading Anxiety: Investigating English-Speaking University Students Learning Chinese as a Foreign Language in $t$ he United States. https://diginole.lib.fsu.edu/islandora/object/fsu:168683/datastream/PDF/view

[2] Arnold, J. (1999). Affect in Language Learning. Beijing: Foreign Language Teaching and Research Press.

[3] Bernhardt, E. B. (1991). Reading development in a second language: Theoretical, empirical, and classroom perspectives. Norwood, NJ: Ablex.

[4] Brantmeier, C. (2005). Anxiety about L2 reading or L2 reading tasks? A study with advanced language learners. The Reading Matrix, 5(2), 67-85.

[5] Cheng, Y. S., Horwitz, E. K., \& Schallert, D. L. (1999). Language anxiety: differentiating writing and speaking components. Language Learning, 49, 417-446.

[6] Cheng, Y. S. (2002). Factors associated with foreign language writing anxiety. Foreign Language Annals, 35, 647-656.

[7] Emre, G. (2014). Using think aloud protocols to identify factors that cause foreign language reading anxiety. Reading Matrix, 2: 109-118.

[8] Horwitz, E. K., Horwitz, M. B, \&. Cope, J. (1986). Foreign language classroom anxiety. The Modern Language Journal, 70, 125-132.

[9] Krashen, S. (1985). The Input Hypothesis: Issues and Implications. London: Longman.

[10] MacIntyre, P. D., \& Gardner, R. C. (1991a). Language anxiety: Its relationship to other anxieties and to processing in native and second languages. Language Learning, 41, 513-534.

[11] MacIntyre P. D., \& Gardner, R. C. (1991). Methods and results in the study of anxiety and language learning: A review of literature. Language Learning, 41 (1):85-117.

[12] Mills, N., Pajares, F., \& Herron, C. (2006). A reevaluation of the role of anxiety: Self-efficacy, anxiety and their relation to reading and listening proficiency. Foreign Language Annals, 39(2), 276-295.

[13] Miyanaga, C. (2007). Anxiety, Strategies, Motivation And Reading Proficiency in Japanese University EFL Learners. Philadelphia: The Temple University.

[14] Philips, E. M. (1992). The effects of language anxiety on students' oral test performance and attitudes. Modern Language Journal, 76:14-26.

[15] Pichette, F. (2009). Second language anxiety and distance language learning. Foreign Language Annals, 1: 77-93.

[16] Saito, Y., Horwits, E. (1999). Foreign language reading anxiety. The Modern Language Journal, 2: 202-218.

[17] Sellers, V. D. (2000). Anxiety in reading comprehension in Spanish as a foreign language. Foreign Language Annals, 33(5): 512-520.

[18] Shi, Y. Z., \& Liu, Z. Q. (2006). Foreign language reading anxiety and its relationship to English achievement and gender. Journal of PLA University of Foreign Languages, 29: 59-65.

[19] Seidenberg, M. S. (1985). The time course of phonological code activation in two writing systems. Cognition, 19, 1-30.

[20] Williams, K. (1991). Anxiety and formal/foreign language learning. RELC Journal, 22, 19-28.

[21] Vogely, A. J. (1998). Listening comprehension anxiety: students' reported resources and solutions. Foreign Language Annals, 31, 67-80.

[22] Young D. (1992). Language anxiety from the foreign language specialists' perspective: Interview with Krashen, Omaggio Hadley, Terrell, and Rardin. Foreign Language Annals, 25: 157-172.

Xiaoli Gan was born in Pengzhou, Sichuan province, China. She is currently an English associate professor in the School of Foreign Languages, Sichuan University of Arts and Science, Sichuan, China. Her research fields include second language acquisition, applied linguistics and English language teaching methodology. 